\title{
A Trust based Reliable Routing Scheme for Wireless Mesh Networks
}

\author{
Pushpender \\ Shri Venkateshwara University \\ Gajraula (UP) \\ India
}

\author{
Sohan Garg, Ph.D \\ C.C.S. University \\ Meerut (UP) \\ India
}

\author{
Yash Pal Singh, Ph.D \\ $S(P G) I T M$ \\ Rewari (HR) \\ India
}

\begin{abstract}
Wireless mobile is a utility tool for communication engineering. Mobility is one of the important characteristics. Due to mobility of nodes in wireless mesh networks, the shortest route is not necessarily the best path. For ensuring the stability of routing path, it is necessary to find out the path that endures a longer time. In this paper based on fuzzy logic, we have proposed a reliable routing scheme to achieve a more reliable route in wireless mesh networks. In this proposed scheme for each node in wireless mesh network, we have to determine three parameters, trust value mobility and battery power, to calculate the lifetime of routes. Each node in network during route discovery, inserts its trust value, battery power and mobility in route request packet. At the destination, by using fuzzy logic mechanism, a new parameter called "reliability value" is generated from inputs trust value, battery power and mobility of each route. The route having more reliability value is selected as a stable route from source to destination. In this paper, we understand the various routing problems related to battery power, node's trust value and mobility of the node in the wireless network.
\end{abstract}

\section{General Terms}

Routing algorithm, Reliable Routing Protocol, WMNs

\section{Keywords}

Mobility, AODV, Trust value, Reliability value, Wireless Mesh Network, Network Interface Cards, Fuzzified, Routing protocol, ESRP, MANET, Signal strength, Mobility

\section{INTRODUCTION}

Wireless communication technology made the revolution in the field of data/voice transmission and receiving system. It not only allows the optimization of existing network but also various technologies have developed, wireless mesh network is one of them. Wireless Mesh Networks are self configurable, self-healing, self-organizing behavioral networks. Like MANETs (Mobile ad-hoc Networks), there are also mobile nodes in the wireless mesh networks (WMNs) and as a result topology of the network is also dynamic. In WMNs, data reaches hop by hop form source to destination. This is possible because each node in WMNs works as a host as well as router. Nodes also contain network interface cards (NICs). Routing in wireless mesh network is a complex process due to its dynamic network conditions. The routing policy of the network is directly affected due to the dynamic behavior of a wireless mesh network. Self-computing based research techniques are demanded due to the complexities associated with dynamic network conditions in WMNs. A lot of research work has been taken out in field of routing protocol for wireless networks by researchers. They have been proposed several types of algorithms having different characteristics. Also a lot of enhancement research work has been proposed in this field. But all these algorithms have their own limitations. Hence a lot of research work has to be done in this field. In our proposed routing scheme, we try to achieve the reliable route or path for the data delivery. In this paper, we have considered three parameters of wireless mesh network. They are battery power, mobility and truth value of nodes. To achieve the fuzzified values of the respective parameters, fuzzy logic system has been utilized. These parameters are used as input variables of the inference engine which gives a reliable value as output. The proposed routing scheme has been simulated in fuzzy logic toolkit of MATLAB 7.2. Present paper consists of six sections. Section 1 tells us about the introduction of wireless mesh network and motivation for the proposed routing scheme for the network. Section 2 describes the related work/literature survey about the proposed research. Section 3 introduces the methodology used for the proposed scheme and its implementation details. Section 4 presents the simulation results, result discussions with input and their respected outputs. Section 5 describes the analysis of the results. And at the last paper is concluded in section 6

\section{LITERATURE STUDY}

Partha Sarathi Banerjee, J.Paul Choudhury,and S.R. Bhadhuri [1] proposed a framework on fuzzy logic based routing in adhoc wireless network. In this work five variables i.e. signal strength, mobility, delay and throughput are used as input and finds out one output parameter named as "route". Here the output of fuzzy logic system is an optimal path. Vineet Bansal, Sohan Garg discussed about the new bandwidth efficient \& network Dependent on-demand routing protocol for MANETs [2]. In this proposed work, fuzzy inference system is used for performance analysis purposes. Three variables bandwidth, signal power and mobility are used as inputs and one output parameter is "Route". This algorithm is implemented using 27 fuzzy inference rules. Arash Dana,Golnoosh Ghalavand,Azadeh Ghalavand and Fordad Farokhi[3] developed a reliable routing algorithm for Mobile Adhoc Networks based on fuzzy logic,where they put emphasis on two parameters, trust value and energy capacity in RREQ packet. In this proposed algorithm, a new parameter is find out from input variables trust value and energy value of each route which is called "Reliability value". The route having maximum reliability value is selected for packet transmission purposes. Arnab Banerjee, Aniruddha, Bhattacharyya and Dipayan Bose [4] discussed about the Power and Trust based secured Routing approach in MANET. In this proposed protocol ESRP (Efficient Secure Routing Protocol works on the basis of trust value which helps the administrator for routing in the wireless network. Nenad Kajic,Irini Reljin and Branimir Reljin[5] proposed a neural networks-based hybrid routing protocol for Wireless Mesh Networks. The proposed protocol is developed using artificial logic-i.e.hopfield neural networks. Protocol is compared with two other already existing protocols. Hopfield neural network is used for enhancing the routing performances. 


\section{RESEARCH METHODOLOGY AND IMPLEMENTATION OF THE PROPOSED SCHEME}

Trust value, battery power capacity and mobility are the three main parameters in this routing mechanism that make the routing scheme more and more reliable. Trust value evaluation is made based on the various factors like the association length, ratio of no. of data packets sent/forwarded successfully by the neighbors to the total number of data packets forwarded to that neighbor and average time take to respond to a RREQ. Hence based on these parameters trust value may be varied. Energy evaluation is defined by the consideration that every node is in high level i.e. it has full capacity. The source will not be considered as a good router to forward the packet if it contains below the half capacity of the total amount of the capacity. The mobility and location of the node may be investigated with the help of a GPS (global positioning system) mechanism. In global positioning system a number of algorithms are used. Reliability evaluation function takes a number of input values based on twenty seven rules that dependent upon varied input variable values i.e. battery power, trust, and mobility values. A fuzzy inference mechanism decides for each three input values which values appear in output. The fuzzy system is made of several components i.e. inference engine, fuzzifier and center average defuzzifier.

Here Fuzzy Logic has been used for routing and management of a Wireless Mesh Network. The proposed fuzzy logic based routing scheme takes into account of three input variables, battery power, mobility and trust value. The absolute value of each of these parameters can take a large range at different points on the network. We have considered the normalized values for each parameter.

Step 1:

"Crisp" normalized values have been converted into fuzzy variables. For this, three fuzzy sets have been defined for each variable. The fuzzy sets, low (from 0 to 0.4 ), medium (from 0.2 to 0.8 ) and high (from 0.6 to 1.0 ) have been used for the input variable battery power. The fuzzy sets, low (from 0 to 0.4 ), medium (from 0.2 to 0.8 ) and high (from 0.6 to 1.0 ) have been used for the input variable mobility. The fuzzy sets, poor (from 0 to 0.4 ), average (from 0.2 to 0.8 ) and high (from 0.6 to 1.0) have been used for the input variable trust value. The fuzzy sets, low (from 0 to 0.4 ), medium (from 0.2 to 0.8 ) and high (from 0.6 to 1.0) have been used for the output variable reliability.
Step 2:

The normalized value of each parameter is mapped into the fine sets. Each value will have some grade of membership function for each set. The memberships that have been defined for each of the fuzzy set for any particular input variable are triangular shape in shape. All the input parameters i.e. battery power, trust value and mobility will have the same kind of properties.

Step 3:

The fuzzy rules of inference have been written. Here total twenty seven rules are derived for this proposed routing scheme. The crisp value of input parameter is given and a defuzzified crisp value for selected parameter is found out from the proposed scheme. An output linguistic variable is used to represent the reliability value. Proposed reliable routes are based upon the fuzzy inference rules for different ranges of the metric i.e. battery power, trust value and mobility availability. The paths are defined as low (from 0 to 0.4 ), medium (from 0.2 to 0.8 ) and high (from 0.6 to 1.0 ) between two mobile nodes. The low represents not reliable path, the medium represents better reliable path or route and the high path indicates the best reliable path between sources to destination. The proposed routing scheme can apply to different routing metrics. These routes have to satisfy the battery power, mobility and trust value requirements of the network. The grade of membership function can be any where between 0 and 1 for each fuzzy set. The defuzzified crisp value for selected parameter is calculated from the proposed scheme.

The problem is to find the reliable and stable route from source to the destination based on battery power, mobility and trust value. The system is based on the fuzzy inference system. The major components of the system consist of the knowledge base, decision making, fuzzification and defuzzification. Now we will write the fuzzy rules based on the battery power, mobility and trust value and try to find out the reliable routing path.

The Fuzzy Inference rules for the proposed routing scheme are mentioned in table 1 . There are twenty seven rules derived for this proposed routing scheme. 
Table 1:Fuzzy Rules

\begin{tabular}{|l|l|l|l|l|}
\hline Rule No. & $\begin{array}{l}\text { Battery } \\
\text { Power }\end{array}$ & Mobility & Trust Value & Reliability Value \\
\hline 1 & LOW & LOW & POOR & LOW \\
\hline 2 & LOW & LOW & AVERAGE & LOW \\
\hline 3 & LOW & LOW & HIGH & MEDIUM \\
\hline 4 & LOW & MEDIUM & POOR & LOW \\
\hline 5 & LOW & MEDIUM & AVERAGE & MEDIUM \\
\hline 6 & LOW & MEDIUM & HIGH & MEDIUM \\
\hline 7 & LOW & HIGH & POOR & LOW \\
\hline 8 & LOW & HIGH & AVERAGE & LOW \\
\hline 9 & LOW & HIGH & HIGH & MEDIUM \\
\hline 10 & MEDIUM & LOW & POOR & LOW \\
\hline 11 & MEDIUM & LOW & AVERAGE & MEDIUM \\
\hline 12 & MEDIUM & LOW & HIGH & HIGH \\
\hline 13 & MEDIUM & MEDIUM & POOR & LOW \\
\hline 14 & MEDIUM & MEDIUM & AVERAGE & MEDIUM \\
\hline 15 & MEDIUM & MEDIUM & HIGH & HIGH \\
\hline 16 & MEDIUM & HIGH & POOR & LOW \\
\hline 17 & MEDIUM & HIGH & AVERAGE & MEDIUM \\
\hline 18 & MEDIUM & HIGH & HIGH & HIGH \\
\hline 19 & HIGH & LOW & POOR & MEDIUM \\
\hline 20 & HIGH & LOW & AVERAGE & HIGH \\
\hline 21 & HIGH & LOW & HIGH & HIGH \\
\hline 22 & HIGH & MEDIUM & POOR & MEDIUM \\
\hline 23 & HIGH & MEDIUM & AVERAGE & MEDIUM \\
\hline 24 & HIGH & MEDIUM & HIGH & MEDIUM \\
\hline 25 & HIGH & HIGH & POOR & LOW \\
\hline 26 & HIGH & HIGH & AVERAGE & MEDIUM \\
\hline 27 & HIGH & HIGH & HIGH & MEDIUM \\
\hline & & & & \\
\hline
\end{tabular}

In this fashion twenty seven rules have been formed depending on the three values 'low', 'medium' and 'high' of the two input variables 'battery power' and 'mobility' and one input variable dependent on "poor", 'average' and 'high'. The out system is the path or route which is either 'low' or "medium" or "high" depending

\section{RESULTS}

A number of test cases have been performed for our routing scheme (see Table 2). Here input values of variables battery on the type of input parameters 'high' means the best reliable routing path for communication in present condition from source to destination on the network.

The simulation work has been performed on Fuzzy Logic Toolbox of MATLAB 7.0.

power, mobility and trust value is indicated. And also their respected output value is also indicated.

Table 2. Test Cases

\begin{tabular}{|c|c|c|c|c|}
\hline & Battery power & Moblity & Trust value & Reliability value \\
\hline Test no. 1 & $\begin{array}{c}0.54 \\
\text { (medium) }\end{array}$ & $\begin{array}{c}0.0802 \\
\text { (low) }\end{array}$ & $\begin{array}{c}0.85 \\
\text { (high) }\end{array}$ & $\begin{array}{c}0.86 \\
\text { (high) }\end{array}$ \\
\hline Test no. 2 & $\begin{array}{c}0.54 \\
\text { (medium) }\end{array}$ & 0.507 (medium) & $\begin{array}{l}0.909 \\
\text { (high) }\end{array}$ & $\begin{array}{l}0.866 \\
\text { (high) }\end{array}$ \\
\hline Test no. 3 & $\begin{array}{c}0.47 \\
\text { (medium) }\end{array}$ & 0.115 (low) & $\begin{array}{c}0.509 \\
\text { (average) }\end{array}$ & $\begin{array}{l}0.814 \\
\text { (high) }\end{array}$ \\
\hline Test no.4 & $\begin{array}{c}0.512 \\
\text { (medium) }\end{array}$ & $\begin{array}{l}0.904 \\
\text { (high) }\end{array}$ & $\begin{array}{l}0.873 \\
\text { (high) }\end{array}$ & $\begin{array}{l}0.859 \\
\text { (high) }\end{array}$ \\
\hline Test no.5 & $\begin{array}{c}0.44 \\
\text { (medium) }\end{array}$ & $\begin{array}{l}0.783 \\
\text { (high) }\end{array}$ & $\begin{array}{l}0.163 \\
\text { (poor) }\end{array}$ & $\begin{array}{l}0.146 \\
\text { (low) }\end{array}$ \\
\hline
\end{tabular}




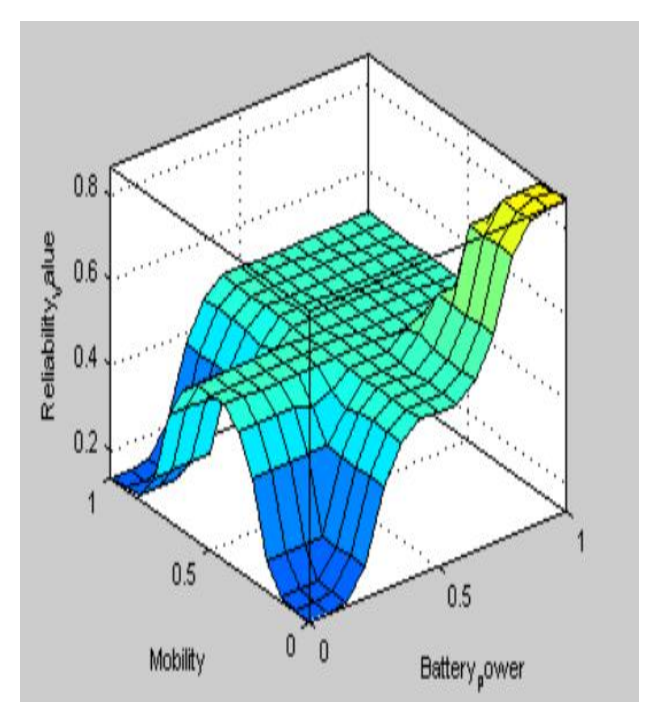

Figure 1: 'Reliability Value' O/P w.r.t. 'Mobility' and 'Battery Power'

Figure 1 shows the reliability value output with respect to mobility and battery power. Mobility and battery power are the fuzzy input variables for the proposed routing scheme which lies on horizontal axes and reliability value is the output which lies on vertical axes.

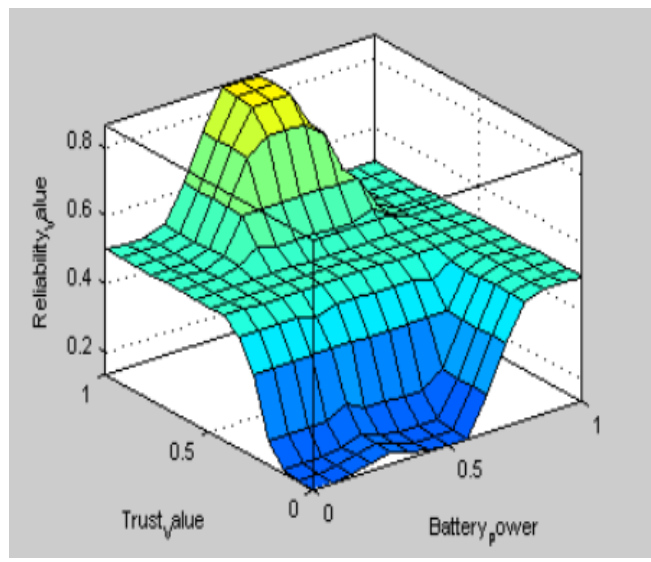

Figure 2: 'Riability Value' $\mathrm{O} / \mathrm{P}$ w.r.t. 'Trust Value' and 'Battery Power'

Figure 2 shows the reliability value output with respect to trust value and battery power. Trust value and battery power are the input parameters for the proposed routing scheme which lies on horizontal axes and reliability value is the output parameter which has been shown on the vertical axes

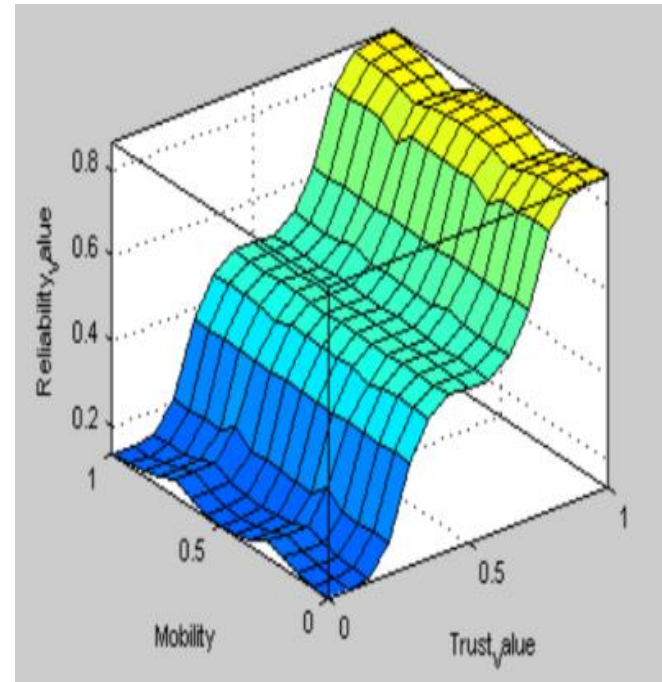

Figure 3: 'Riability Value' O/P w.r.t. 'Mobility' and 'Trust Value'

Figure 3 shows the reliability value output with respect to mobility and trust value. Mobility and trust value are the fuzzy input parameters for the proposed scheme which lies on the horizontal axes and reliability value is the output parameter which has been shown on the vertical axes. The When battery power is medium (0.512), mobility is low $(0.0904)$ and trust value is high $(0.873)$ then in this condition (see figure 4$)$ the route is high (0.859). So this algorithm works well when mobility is low and battery power is medium.

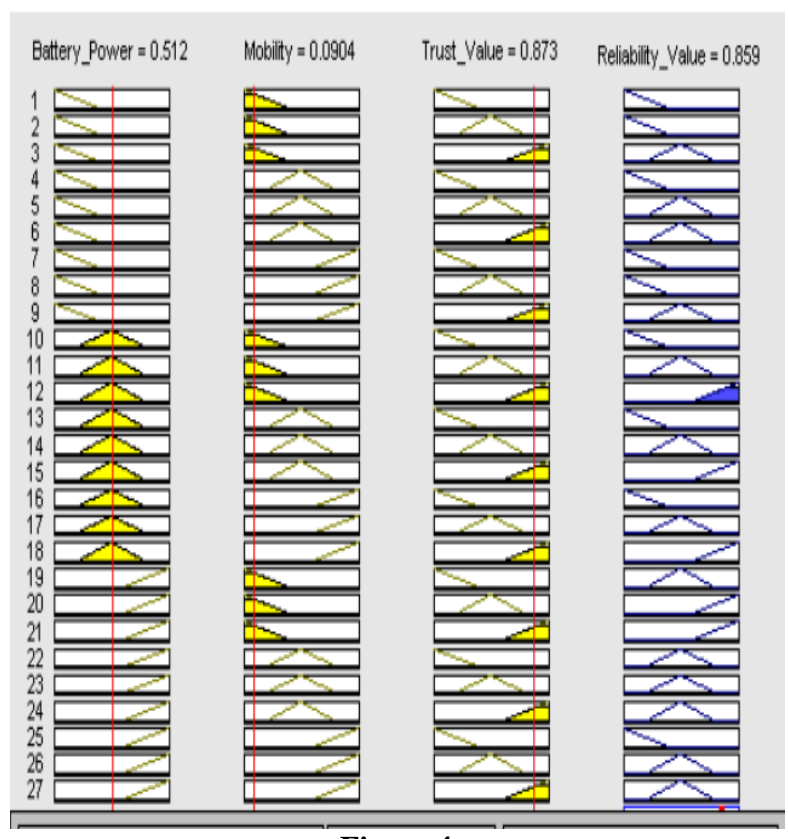

Figure 4 


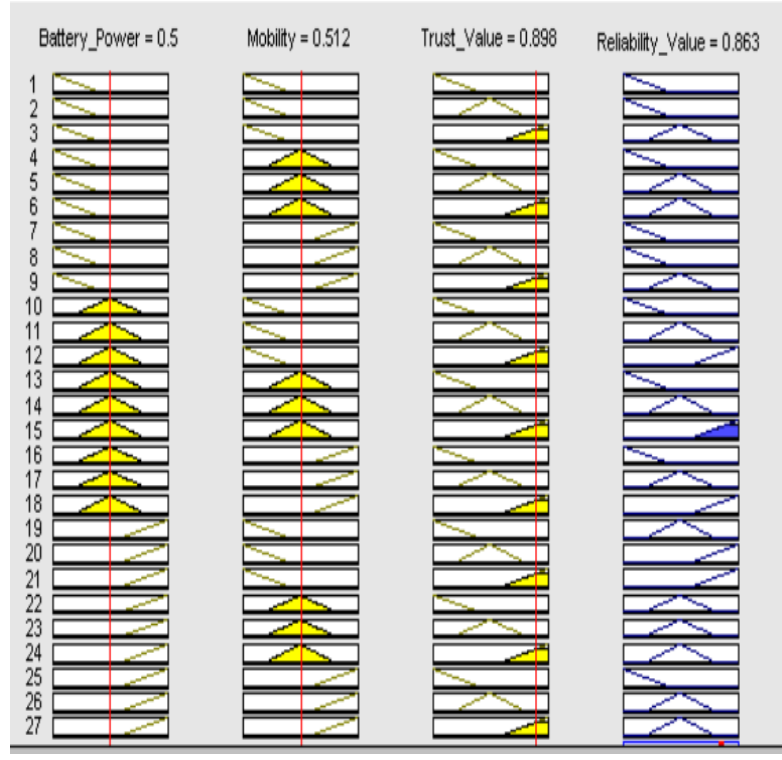

Figure 5

In figure 5 we have seen that route is high at low mobility, medium battery power and at high trust value but against it when we increase the mobility towards medium $(0.512)$ at medium battery power $(0.5)$ and high trust value $(0.863)$ the route is again high i.e. best reliable route. So this routing scheme works well at medium mobility also. This is very clear from the figure 6 that in this routing scheme the value of the battery power (0.464) and mobility (0.102) is same as in figure 4 but the difference is that when we will decrease the trust value up to average $(0.512)$ then the reliability value is still high i.e. best reliable route, but as we will increase the mobility then the reliability value will be medium i.e. better reliable route.

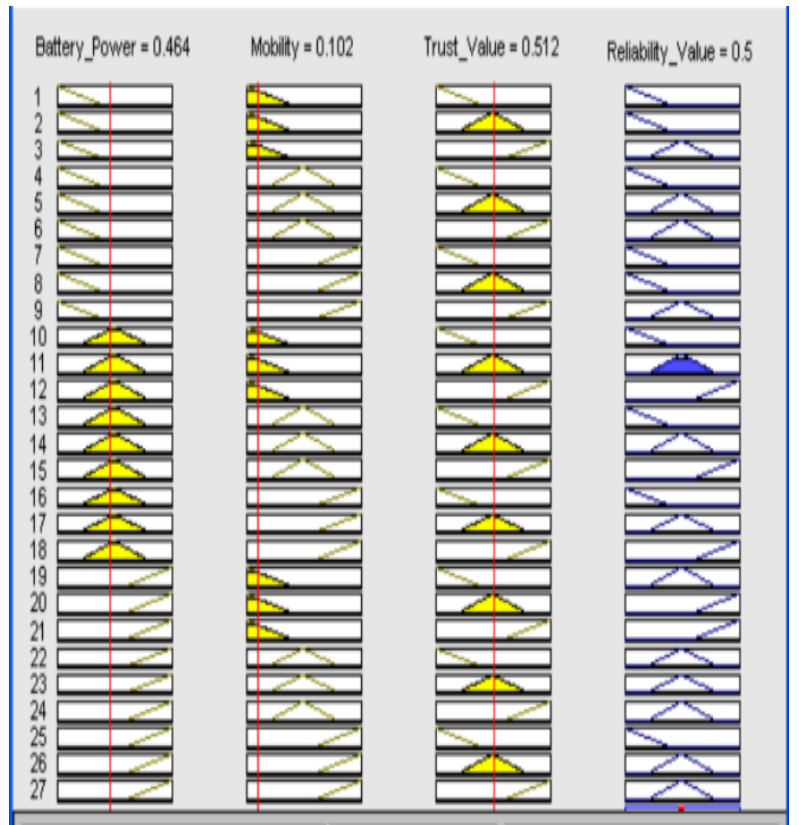

Figure 6

\section{ANALYSIS OF THE RESULTS}

- Simulation results shows that the proposed routing scheme works well when battery power is low because at low battery power the reliability value is medium.

- When battery power is constant and mobility is increasing, the reliability value also increased from medium stage to high stage.

- When battery power is low and mobility is also increasing the reliability value is also increased i.e. routing algorithm will works well at high mobility of node also.

- When battery power is high and mobility is increasing, the reliability value is reached from high to medium, but when battery power is high and mobility is also increasing, trust value goes from high to poor at that stage reliability value is at medium stage.

- At constant battery power, when trust value is increasing and as a result reliability value goes from medium to high.

- At last, simulation results shows that proposed routing scheme works well at low battery power and also work well at high mobility of nodes on the network also.

\section{CONCLUSION}

The proposed new routing scheme is based on battery power, mobility and trust value, where the segmentation of nodes will substantially reduces the overhead of the entire wireless network and enhancing the packet delivery at a stable route. The experimental work indicates that the proposed routing scheme works well when battery power is low because at low battery power the reliability value is medium. Besides this, the proposed routing scheme is also reliable and applicable when mobility of a node is high. Our proposed scheme combines three parameters to discover a reliable route between the sources to destination. During route discovery, node with more trust value, maximum battery power and low mobility is selected as a router based on a parameter called "Reliability Value". The proposed routing scheme maintains a reliable path from source to destination thus enhancing network life time and reduces number of packet loss during packet transmission. Simulation results indicate that proposed routing scheme has significant reliability enhancement as compared to other routing algorithms such as AODV. The simulation results show that our routing scheme is functional and effective.

\section{REFERENCES}

[1] Paras Sarathi Banerjee,J.Paul Choudhury,S.R. Bhadra Choudhuri, "A Framework on Fuzzy Logic Based Routing in Ad-Hoc Wireless Network", International Journal of Computer Information Systems,vol.3,No.6,2011,pp.62-72.

[2] Vineet Bansal, Sohan Garg, "A new Bandwidth Efficient \& Network Dependent on-Demand Routing Protocol for MANETs, "IJARCSSE,vol.2,Issue7,July 2012,pp.200-206.

[3] Arash Dana, Golnoosh Ghalavand,Azadeh Ghalavand and Fordad Farokhi, "A Reliable routing algorithm for Mobile Adhoc Networks based on fuzzy logic", International Journal of Computer Science Issues (IJCSSI), vol.8,Issue3,No.1,May 2011,pp.128-133. 
[4] Arnab Banerjee, Aniruddha, Bhattacharyya and Dipayan Bose, "Power and Trust based secured Routing approach in MANET", International Journal of Security, Privacy and Trust Management (IJSPTM), vol.1,No. 3/4,August 2012,pp.37-51.

[5] Nenad Kajic, Irini Reljin and Branimir Reljin, "A Neural Networks-Based Hybrid Routing Protocol for Wireless Mesh Networks", Sensors 2012, 12, pp.7548-7578.

[6] S. Swapna Kumar,M.Nanda Kumar, V.S. Sheela, K.R. Kashwan," Cluster Based Routing Algorithm Using Dual Staged Fuzzy Logic in Wireless Sensor Networks", Journal of Information \& Computational Science 9:5,May 2012,pp. 12811297.

[7] Pushpender, Prof. (Dr.) Sohan Garg, Prof. (Dr.) YashPal Singh, "Performance /efficiency enhancement of Dynamic Source Routing Protocol in Wireless Mesh Networks", Journal of Engineering Research and Application www.ijera.com, Vol. 3, Issue 5, Sep-Oct 2013, pp.991-995, ISSN: 2248-9622.

[8] Jishan Mehedi and Mrinal Kanti Naskar," A fuzzy Based Distributed Algorithm for Maintenance Connected Network Topology in Mobile Ad-Hoc Networks Consisting Freeway Mobility Model", Journal of Computing and Information Technology, CIT 20, 2012, pp. 69-84.

\section{ABOUT THE AUTHOR'S}

1. Er. Pushpender Sarao received the B.Tech degree in Information Technology from DAV College of Engineering \&Technology, Kanina (India) affiliated to MDU, Rohtak and M.Tech degree in Computer Science \& Engineering from Maharshi Dayanand University, Rohtak (India). He has been in teaching profession more than four years. Beside he has the good industrial exposure in the field of computer technology, manufacturing industries, and network. He is a research scholar pursuing his Ph.D from Shri Venkateshwara University, Gajraula, JP Nagar (UP), India in Wireless Mesh Network specializing Routing algorithms and their enhancements.

2. Prof. (Dr.) Sohan Garg: Presently working as Director, Sir Chhotu Ram Institute of Engineering and Technology, C.C.S. University Campus Meerut, UP (India). He has worked as Director, IIMT Management College, Meerut, (UP), India. $\mathrm{He}$ received the $\mathrm{Ph} . \mathrm{D}$. degree in Computer Science \& Engineering from Institute of Advanced Studies, C.C.S. University Campus Meerut (India). He received the M.Tech degree in Computer Science \& Engineering from M.B. University, H.P (India). He has published several research papers in national and international journals in his credit. $\mathrm{He}$ is also the guide of research scholars for almost dozen of Universities.

3. Prof. (Dr.) Y.P.Singh: presently working as Director, Somany (PG) Institute of Technology \& Management, Rewari (India). He has published 60 research papers in national and international journals in his credit. $\mathrm{He}$ is also guide and supervisor almost for dozen of universities. His area of research is communication engineering, wireless networks, satellite communication and light-fidelity etc. He has awarded with 'Best Teacher award' in 2004, 2012, 2013 by Trainer and Technical department, Govt. of Delhi. He has also won "Jewel of India" award in 2014 